\title{
Spectrophotometric Determination of Vitamin C Using 3-Hydroxy-2-aryl-4H-chromen-4-one as Analytical Reagent
}

\author{
ASHWANIKUMAR* and PANKAJ BHATIA \\ Department of Chemistry, Kurukshetra University, \\ Kurukshetra-136119, Haryana, India \\ vihanaashwani@gmail.com
}

Received 6 April 2017 / Accepted 1 May 2017

\begin{abstract}
A simple and rapid spectrophotometric method for the determination of ascorbic acid is described. It involves the reduction of iron(III) to iron(II) with ascorbic acid and the formation of brown coloured complex by the reaction of iron(III) with 3-hydroxy-2-aryl-4H-chromen-4-one, followed by the extraction of the complex into chloroform and measuring the absorbance at $405 \mathrm{~nm}$. The Beer's law is obeyed up to $2.4 \mu \mathrm{gmL}^{-1}$ of ascorbic acid having molar absorptivity and Sandell's sensitivity of $5.897 \times 10^{5} \mathrm{~L} \mathrm{~mol}^{-1} \mathrm{~cm}^{-1}$ and $2.986 \times 10^{-4} \mu \mathrm{g} \mathrm{cm}^{-2}$ respectively. The interference of various substances commonly added to pharmaceuticals was studied. The procedure has been applied to the assay of pharmaceutical preparations containing vitamin C.
\end{abstract}

Keywords: Spectrophotometry, Absorption, HAC, Ascorbic acid, Extraction

\section{Introduction}

Many methods based on iron(III)-iron(II) system have been proposed for the assay of ascorbic acid samples of diverse nature. These procedures involve the reagents such as $2,2^{\prime}$-bipyridyl $1^{1-5}$, 1-10-phenanthroline ${ }^{6-10}, 2$-(5-bromo-2-pyridylazo)-5-dimethylaminophenol ${ }^{11}$, Nitroso- $R$-salt $^{12}$ and ferrozine ${ }^{13-15}$ etc. The methods involving 2-2'-bipyridyl and 1,10-phenanthroline find extensive use in the development in the analysis of vitamin C. Many of these methods are time consuming as full colour development takes 30-60 min. Method using 1,10-phenanthroline need either background correction as done by $\mathrm{Cu}$-catalysed oxidation ${ }^{16}$ or the addition of $\mathrm{NH}_{4} \mathrm{~F}$ as the inhibitor of the light reduction of iron(III)- $O$-phen complex.

Recently simplification of the procedure involving 3-hydroxy-2-(2-thienyl)-4Hchromen-4-one complex has been reported 3-hydroxy-2-aryl-4H-chromen-4-one (HAC) has been found to be a suitable reagent that forms a coloured complex with iron(III) in almost neutral solutions which requires only one min waiting time instead of 30 or $60 \mathrm{~min}$. The complex is extracted into chloroform to give a reddish brown extract. The method based on the extraction of iron(III)-HAC complex provides the desirable features of simplicity and rapidly besides having better sensitivity and selectivity. The detailed studies pertaining to the proposed method are presented here. 


\section{Experimental}

A Hitachi Schimadzu spectrophotometer (model UV-140-02) with a pair of matched $1 \mathrm{~cm}$ quartz cells was used for absorbance measurements.

\section{Reagents}

Iron(III) solution

$1 \mathrm{mg} \mathrm{mL} \mathrm{L}^{-1}$ iron(III) solution was prepared by dissolving accurately weighed amount of ammonium ferric sulphate in $100 \mathrm{~mL}$ of deionised water containing $0.5 \mathrm{~mL}$ of concentrated sulphuric acid. A lower concentration $\left(10 \mu \mathrm{gmL}^{-1}\right)$ was obtained by dilution of the stock solution.

\section{3-Hydroxy-2-aryl-4H-chromen-4-one (HAC) solution}

$0.05 \%(\mathrm{w} / \mathrm{v})$ solution was obtained by dissolving the reagent (Figure 1) in ethanol.<smiles>O=c1c(O)c(-c2ccccc2)oc2ccccc12</smiles>

\section{Ascorbic acid}

Figure 1. 3-Hydroxy-2-aryl-4H-chromen-4-one (HAC)

A fresh aqueous solution of ascorbic acid $(100 \mu \mathrm{g} / \mathrm{mL})$ was used. A lower concentration $\left(10 \mu \mathrm{gmL}^{-1}\right)$ was obtained by dilution of the stock solution. Deionized water was used for preparing solutions and all the reagents used were of analytical grade.

\section{Procedure}

Into a $100 \mathrm{~mL}$ separatory funnel, $10 \mu \mathrm{g}$ of iron(III) solution was pipetted followed by the addition of an aliquot of ascorbic acid and $0.5 \mathrm{~mL}$ of HAC solution. Enough water was added to make the aqueous phase to $10 \mathrm{~mL}$. The resulting complex was extracted for $30 \mathrm{~s}$ with $10 \mathrm{~mL}$ of chloroform. The coloured extract was taken into a $10 \mathrm{~mL}$ volumetric flask and the volume was made up to the mark with chloroform, if required. The absorbance of the reddish brown complex was measured at $405 \mathrm{~nm}$ against the reagent blank prepared similarly and the vitamin $\mathrm{C}$ content was determined from the calibration curve constructed under the optimum conditions of the procedure.

\section{Analysis of tablets /capsules}

The tablets or capsules (5-7 items) were crushed into powder form and a known weight equivalent to $100 \mathrm{mg}$ of ascorbic acid was dissolved in deionized water. The solution was filtered into a $100 \mathrm{~mL}$ volumetric flask and made up to the volume. A lower concentration $(100 \mu \mathrm{g} / \mathrm{mL})$ was obtained by suitable dilution of this solution. The diluted solution was analysed by the proposed procedure.

\section{Results and Discussion}

\section{Spectral characteristics}

The electronic spectrum of iron(III)-HAC complex was studied over the range 375-720 nm which shows one absorption band in the region 405-407 $\mathrm{nm}$ (Figure 2). The complex absorbs strongly at $405 \mathrm{~nm}$, where minimum absorption was shown by the blank. Therefore, absorbance measurements were made at $405 \mathrm{~nm}$. 


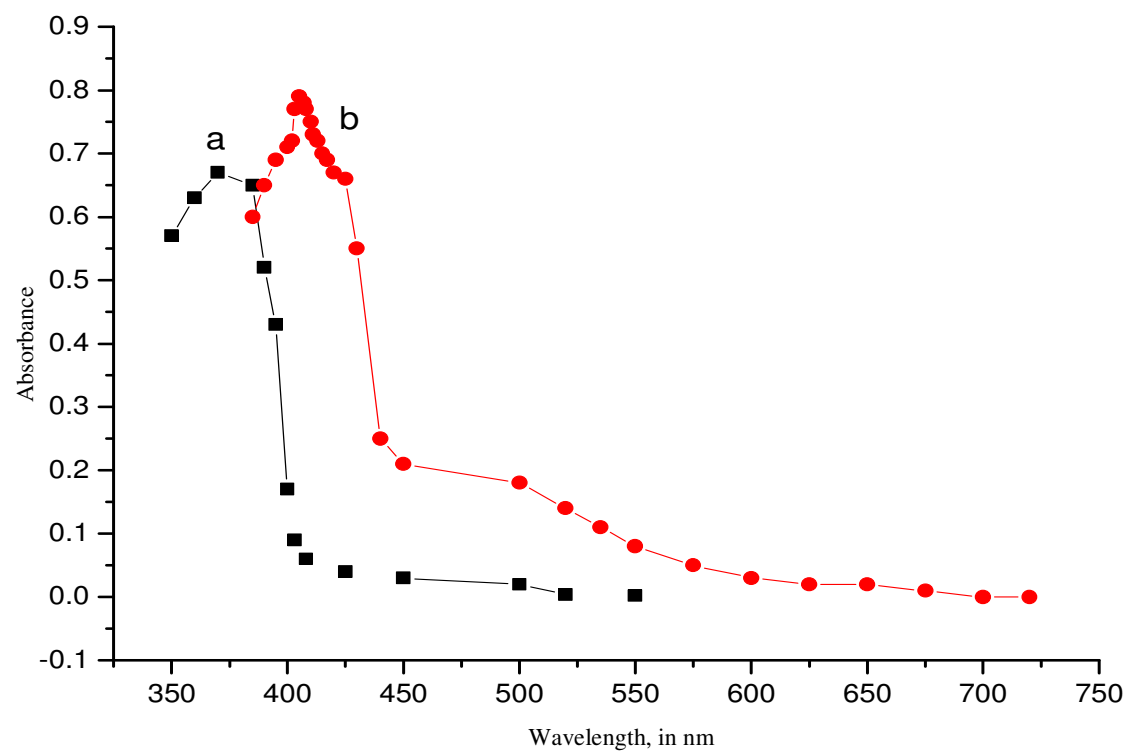

Figure 2. Absorption spectrum of iron(III)-HAC complex in chloroform. (Conditions: $\mathrm{Fe}(\mathrm{III})=10 \mu \mathrm{g} ; \mathrm{HAC}$ solution $=0.5 \mathrm{~mL}) \mathrm{a}$-Reagent blank against chloroform. $\mathrm{b}-$ Complex against reagent blank

\section{Effects of reaction variables}

The various parameters which can influence the extraction and absorbance of the complex as well were studied. These include the changes in concentration of the reagent, $\mathrm{pH}$, equilibration time and temperature. For such studies, the aqueous solution containing, $10 \mu \mathrm{g}$ of iron(III) was equilibrated with an equal volume of chloroform for $30 \mathrm{~s}$. The other conditions used therein are indicated in Table 1.

Table 1. Optimization of reaction variables

\begin{tabular}{cccccc}
\hline HAC volume, in $\mathrm{mL}$ & 0.1 & 0.2 & $0.4-1.0$ & 2.0 & \\
\hline Absorbance & 0.26 & 0.53 & 0.73 & 0.70 & \\
pH & 1.5 & 2.0 & $3.5-8.5$ & 9.0 & 10.2 \\
Absorbance & 0.43 & 0.63 & 0.73 & 0.67 & 0.63 \\
Equilibration time & 0.15 & $0.30-1.00$ & & & \\
(in min.) & & & & & \\
Absorbance & 0.70 & 0.73 & & & \\
Temperature & $20-35$ & 40 & 45 & 50 & \\
Absorbance & 0.73 & 0.70 & 0.68 & 0.67 & \\
\hline
\end{tabular}

Conditions: Iron $(I I I)=10 \mu \mathrm{g}$; volume of reagent $(H A C)$ solution $=0.5 \mathrm{~mL}$; equilibration time $=30 \mathrm{~s}$; volume of aqueous phase $=10 \mathrm{~mL}$; volume of chloroform $=10 \mathrm{~mL} ; \lambda_{\max }=405 \mathrm{~nm}$

\section{Effect of HAC concentration}

An increase in the HAC concentration up to $0.4 \mathrm{~mL}$ of the reagent solution enhances the absorbance of the complex which thereafter remains the same up to $1.5 \mathrm{~mL}$ but there is a gradual decrease in absorbance above this concentration (Table 1, Figure 3 Curve A). Hence $0.5 \mathrm{~mL}$ of the HAC solution was used for further studies. 


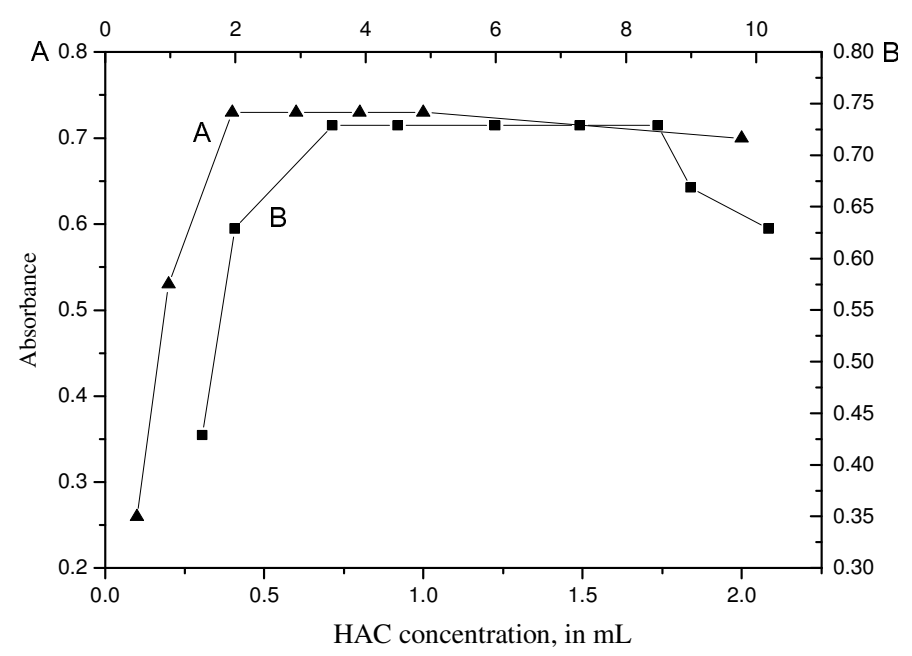

Figure 3. Effect of HAC concentration

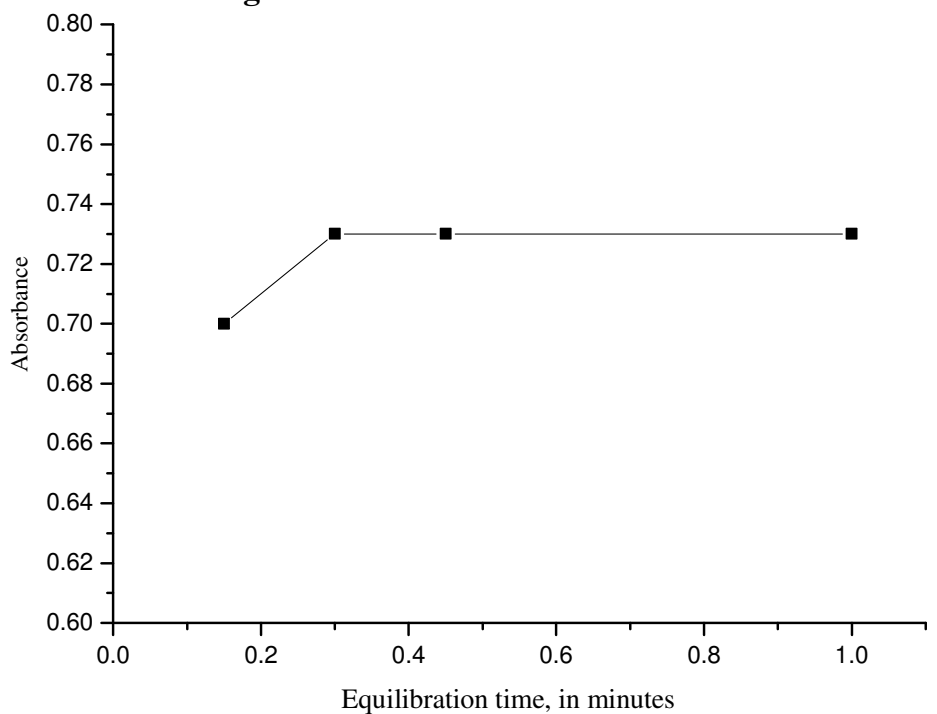

\section{Effect of $p H$}

Figure 4. Effect of equilibration time $\mathrm{B}$ effect of $\mathrm{pH}$

The extraction of the Fe(III)-HAC complex was studied over a pH range 1.5-10.2. It was observed that the complex gives maximum absorbance within range of $\mathrm{pH}$ 3.5-8.5 (Table 1, Figure 3, Curve B). However, a decrease is observed on going to either side of the range.

\section{Effect of the equilibration time}

An increase in the time contact between two phases up to $30 \mathrm{~s}$ enhances the extraction as evidenced by corresponding by increase in the absorbance of the complex. It remains constant up to $1 \mathrm{~min}$ of equilibration time (Table 1, Figure 4). Therefore, equilibration time of $30 \mathrm{~s}$ was chosen. 


\section{Effect of temperature}

The effect of temperature of aqueous solution was found to have little effect on the absorbance of the complex over the range $20-35{ }^{\circ} \mathrm{C}$ (Table 1 ).

\section{Choice of solvent}

The extraction behaviour of the complex in different solvents was studied as shown in Table 2. Among the solvents tested, dichloromethane, benzene, chloroform, carbon tetrachloride, xylene was found to extract the complex. While it was little extracted into iso-amyl acetate and isopropyl alcohol. Chloroform was chosen as an extractant because it gave the highest absorbance.

Table 2. Extraction behaviour of the complex in different solvents

\begin{tabular}{cc}
\hline Solvent & Absorbance $^{*}$ \\
\hline Chloroform & 0.73 \\
Dichloromethane & 0.70 \\
Carbon tetrachloride & 0.69 \\
Benzene & 0.65 \\
Xylene & 0.39 \\
$n$-Hexane & 0.17 \\
Iso-Amyl acetate & 0.00 \\
Iso-Propyl alcohol & 0.00 \\
\hline "Measured against respective blank
\end{tabular}

\section{Beer's law and statistical parameters}

Under the optimum conditions, a standard calibration curve was constructed at $405 \mathrm{~nm}$ by adding different amount of ascorbic acid to iron(III) solution. A linear relationship between absorbance and concentration of the analyte was observed over the range $0.0-2.4 \mu \mathrm{gmL}^{-1}$ (Table 3, Figure 5).

\section{Interference studies}

The effect of possible ingredients likely to be present in pharmaceutical products was studied. The result of such studies is shown in Table 4, where the different substances are classified under the headings sugars, vitamins and amino acids, organic acids, cations and anions etc. Sugars are tolerated in good amounts at the levels indicated but the tolerance limit for the studied vitamins and amino acids is comparatively low especially with riboflavin, cyanocobalamin, cysteine and folic acid. Organic acids other than tartaric acid, salicylic acid and citric acid do not interfere. Among the tested cations and anions, $\mathrm{Mn}$ (II), $\mathrm{Co}(\mathrm{II})$ and $\mathrm{Zn}$ (II) are tolerated in traces whereas $\mathrm{Al}(\mathrm{III})$ and sodium thiosulfate interfere seriously with the determination. Some other substances as mentioned under the heading 'miscellaneous' are also tolerated.

Table 3. Absorbance values at different concentration of ascorbic acid

\begin{tabular}{cc}
\hline Amount of ascorbic acid, $\mu \mathrm{g} / 10 \mathrm{~mL}$ & Absorbance \\
\hline 0 & 0.73 \\
2 & 0.67 \\
6 & 0.48 \\
8 & 0.45 \\
10 & 0.38 \\
12 & 0.27 \\
20 & 0.15 \\
24 & 0.04 \\
\hline
\end{tabular}




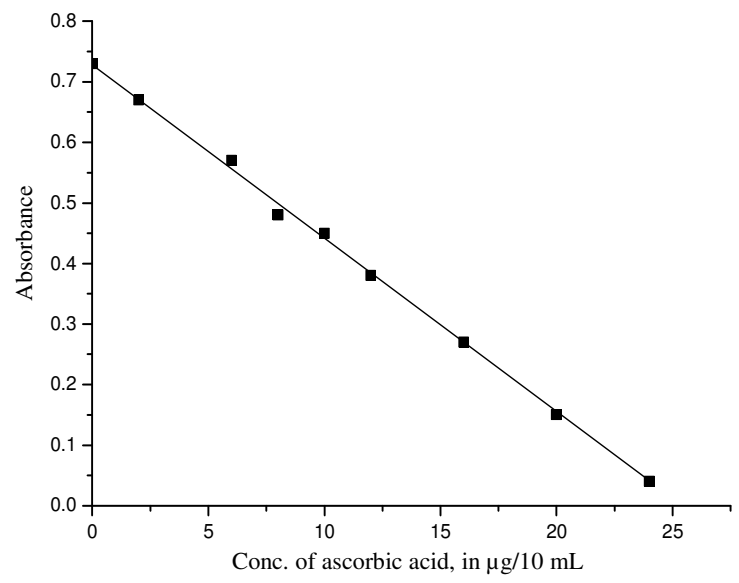

Figure 5. Beer's law curve for ascorbic acid

Table 4. Effect of diverse substances

\begin{tabular}{|c|c|c|}
\hline & Substance added ${ }^{\#}$ & Tolerance limit (mg per $10 \mathrm{~mL}$ ) \\
\hline \multirow[t]{4}{*}{ Sugars } & Sucrose & 100 \\
\hline & Glucose, Fructose & 200 \\
\hline & Maltose & 150 \\
\hline & Lactose & 50 \\
\hline \multirow[t]{9}{*}{ Vitamins \& Amino Acids } & Pyridoxine hydrochloride & 4.0 \\
\hline & Thiamine hydrochloride & 5.0 \\
\hline & Methionine, asparaticacid & 5.0 \\
\hline & Folic acid & 0.05 \\
\hline & Riboflavin, cyanocobalamin & 0.1 \\
\hline & Nicotinic acid & 5.0 \\
\hline & Glutamic acid & 1.0 \\
\hline & Nicotinamide & 0.6 \\
\hline & Cysteine & 0.03 \\
\hline \multirow[t]{6}{*}{ Organic acids } & Benzoic acid & 10 \\
\hline & Succinic acid & 2.0 \\
\hline & Maleic acid & 7.0 \\
\hline & Tartaric acid & 0.5 \\
\hline & Salicylic acid & 0.5 \\
\hline & Citric acid & 0.05 \\
\hline \multirow[t]{8}{*}{ Cations and anions } & $\mathrm{Ca}(\mathrm{II}), \mathrm{Mg}(\mathrm{II})$ & 5.0 \\
\hline & $\mathrm{Co}(\mathrm{II}), \mathrm{Mn}(\mathrm{II})$ & 0.03 \\
\hline & $\mathrm{Zn}(\mathrm{II})$ & 0.8 \\
\hline & $\mathrm{Al}(\mathrm{III})$ & 0.1 \\
\hline & $\mathrm{Cl}^{-}, \mathrm{SO}_{4}^{2-}$ & 40 \\
\hline & $\mathrm{NO}_{3}^{-}$ & 5.0 \\
\hline & $\mathrm{F}^{-}$ & 2.0 \\
\hline & $\mathrm{S}_{2} \mathrm{O}_{3}^{2-}$ & 0.4 \\
\hline \multirow[t]{4}{*}{ Miscellaneous } & Acetone & 200 \\
\hline & Formaldehyde & 150 \\
\hline & Thiourea, Urea & 100 \\
\hline & Glycerol & 80 \\
\hline
\end{tabular}

${ }^{\#}$ Substances were added prior to the addition of ascorbic acid 


\section{Applications}

The worked out method for the determination of ascorbic acid is fast and facile. The method is quite useful and allows satisfactory determination of ascorbic acid in the presence of common ingredients in pharmaceutical formulations (Table 5).

Table 5. Analysis of pharmaceutical products

\begin{tabular}{cccc}
\hline S.No & Preparation & Ascorbic acid content per tablet, in mg \\
\hline & & Claimed & Found \\
\hline 1 & Celin & 500 & 498.5 \\
2 & Limcee & 100 & 98.7 \\
3 & Supradyn (multivit.) & 150 & 145.8 \\
4 & Celin( Chewable) & 200 & 198.2 \\
\hline
\end{tabular}

\section{References}

1. Sicki B I, Mimnough E G and Gram T E, Biochem Pharmacol., 1977, 26(21), 20372041; DOI:10.1016/0006-2952(77)90013-2

2. $\quad$ Arya S P and Mahajan M, Proc Natl Acad Sci., India, 1997, 67, 39.

3. Okamura M, Clin Chim Acta, 1980, 103(3), 259-268; DOI:10.1016/00098981(80)90144-8

4. Fathi M R, Elahi R and Hashemi P, Chemia Analtyczna (Warsaw, Poland,), 2005, 50, 1069.

5. Kleszczewska, Ewa, J Trac Micro Tech., 2003, 21, 85.

6. Pang Y and Xu J, Yaowa Fenxi Zazhi, 1984, 4, 350.

7. Lu X and Xiao Y, LithuaJianyanHuaxue Fence, 1991, 27, 289.

8. Besada A, Talanta, 1987, 34(8), 731-732; DOI:10.1016/0039-9140(87)80229-1

9. Teshima N, Nobuta T and Sakai T, Bunseki Kagaku, 2008, 57, 327.

10. Wei-Xing Ma, Ou Shao, Hai-Hong Jia, Ying-Hong Liu and Xing-You Xu, Shiyan Jishu Yu Guanli, 2008, 25, 41.

11. Ferreira Sergio L C, Bandeira Marcus L S F, Lemos Valfredo A, Dos Santos Hilda C and Costa A C Spinola, Frencius J Nal Chem., 1997, 357(8), 1174-1178; DOI:10.1007/s002160050326

12. Arya S P and Mahajan M, Anal Lett., 1997, 30(14), 2541-2553; DOI:10.1080/00032719708001764

13. Suzuki M, Takayanagi M and Yashiro T, Rinsho Kagaku, 1985, 14, 399.

14. Butts W C and Mulvihill H J, Clin Chem., 1975, 21(10), 1493-1497.

15. Molina-Diaz A, Ortega-Carmona I and Pascual-Reguera M I, Talanta, 1998, 47(3), 531-536; DOI:10.1016/S0039-9140(98)00085-X

16. Lau O W and Luk S F, J Assoc Off Anal Chem., 1987, 70(3), 518-520. 